\title{
Four in vitro activities of apigenin to human colorectal carcinoma cells susceptible to air-oxidative and heating treatments
}

\author{
Bo Wang ${ }^{1,2}$, Xin-Huai Zhao ${ }^{1 *}$ \\ ${ }^{1}$ Key Laboratory of Dairy Science, Ministry of Education, Northeast Agricultural University, Harbin 150030, PR China, ${ }^{2}$ College of Pharmacy, \\ Heilongjiang University of Chinese Medicine, Harbin 150040, PR China
}

\section{A B S TR A C T}

\begin{abstract}
Flavonoids as the important natural phytochemicals have been widely assessed for their healthcare functions in recent years. Apigenin, one member of the flavonoid family, was dissolved in aqueous solution, and subjected to respective air-oxidative and heating treatments in this study to result in partial apigenin degradation. Impacts of the two treatments on apigenin's four in vitro activities to a human colorectal carcinoma line (HCT-116 cells) were assessed, in terms of growth inhibition, apoptosis induction, mitochondrial membrane potential (MMP) loss, and generation of intracellular reactive oxygen species (ROS). The results indicated that apigenin in dose-timedependent manner inhibited the growth of the cells, and showed stronger anti-proliferation at $160 \mathrm{mmol} / \mathrm{L}$ than the air-oxidized or heated apigenin $(67.4 \%$ versus $65.1 \%$ or $50.1 \%)$ at same dose level. Apigenin was also more powerful than the air-oxidized or heated apigenin to cause the cells with death morphology and MMP loss. In comparison with the air-oxidized or heated apigenin, apigenin at $160 \mathrm{mmol} / \mathrm{L}$ conferred the treated cells with more apoptotic cells $(29.3 \%$ versus $28.3 \%$ or $8.3 \%)$ and much enhancement of the intracellular ROS $(300.7 \%$ versus $247.3 \%$ or $201.7 \%)$, demonstrating that the treated apigenin had weaker apoptosis induction and pro-oxidation than the untreated apigenin. It is thus concluded that the four anti-cancer properties of apigenin in terms of anti-proliferation, MMP loss, death or apoptosis induction, and pro-oxidation were all susceptible to (i.e. weakened by) the air-oxidative and especially heating treatments.
\end{abstract}

Keywords: Apigenin; Heating treatment; Air-oxidation; Anti-cancer activity; Human colorectal carcinoma cells

\section{INTRODUCTION}

Colorectal carcinomas following lung cancer are the second leading causes of cancer related deaths in the whole word (Ahmed et al., 2013). Modern medical treatment of advanced colon cancer is still limited. At the same time, chemotherapeutics often lead to unpleasant side effects (Siddique et al., 2008). Consumption of fruits and vegetables has been demonstrated to have chemopreventive potential to prevent cancer development in the body, as some small molecules (e.g. polyphenols) from these plant foods have anti-oxidant, anti-inflammatory, and anti-carcinogenic properties (Marchand, 2002). Many studies have assessed anti-caner activities of these small molecules. Citrus flavonoids have growth inhibition on the HepG2, HL-60 and MDA-MB-231 cancer cells (Zhang et al., 2014). Total flavonoids isolated from Korean citrus can arrest the A549 cells at G2/M-phase, and induce apoptosis via regulating the expression levels of caspase, cleaved PARP, and Bax/Bcl-xL (Park et al., 2012). Flavones and flavonols show in vitro anti-cancer activities to both human oesophageal adenocarcinoma and squamous cell carcinoma cells by inducting $\mathrm{G} 2 / \mathrm{M}$ arrest and apoptosis (Zhang et al., 2008; Zhang et al., 2009). Artocarpesin, cycloartocarpesin, and isobavachalcone all have cytotoxic effects on the hepatocarcinoma HepG2, colon carcinoma HCT-116, leukemia CCRF-CEM, and other six cancer cells (Kuete et al., 2015). Following other four flavonoids quercetin, kaempferol, myricetin, and luteolin, apigenin (4',5,7-trihydroxyflavone) is one of the most common flavonoids in plant foods, and estimated to be consumed by Hungarian children and adults at $0.57-0.87 \mathrm{mg} /$ day (Meyer et al., 2006). Apigenin is considered as non-mutagenic and non-toxic to normal cells (van Dross et al., 2003), but has anti-cancer activities to several cancer cells in terms of antiproliferation, cell cycle alteration, and apoptosis induction

\footnotetext{
*Corresponding author:

Xin-Huai Zhao, Key Laboratory of Dairy Science, Ministry of Education, Northeast Agricultural University, Harbin 150030, PR China. Tel.: +86 4515519 1813, Fax: +86 4515519 0340. E-mail: zhaoxh@neau.edu.cn
}

Received: 22 August 2016; Revised: 09 January 2017; Accepted: 11 January 2017; Published Online: 28 January 2017 
(Shukla et al., 2014). Apigenin in a dose-time-dependent manner can inhibit cell growth and cause G2/M cell cycle arrest in three cancer cells (SW480, HT-29, and Caco-2) (Wang et al., 2000). Apigenin also has anti-cancer effect on the breast cancer MDA-MB-468 cells via inhibiting cell growth and reducing phosphorylation of Akt (protein kinase B) (Harrison et al., 2014), as Akt phosphorylation is a fetal in the phosphatidylinositide 3-kinase pathway to promote tumor growth and progression. A recent study has shown that apigenin is a potent promoter to activate caspase pathway in the human leukemia cells (U937, THP-1 and HL60) (Jayasooriya et al., 2012).

However, human beings consume raw or fresh plant foods as well as the processed plant foods. The quality, quantity, and bio-activities of flavonoids in these processed plant foods can be affected by processing conditions (Igual et al., 2013; Escriche et al., 2014; Rodríguez-Roque et al., 2015). Processing methods (e.g. heating, mechanical, and domestic processes) and the storage period can directly affect flavonoid contents and consequently anti-oxidant properties of these processed plant foods (Yao and Ren, 2011; Marszałek et al., 2015). Several studies prove that food processing can enhance anti-oxidant properties of flavonoids, whereas others studies give opposite conclusions (Trumbo et al., 2003; Ryan et al., 2010; Velázquez-Estrada et al., 2013). In general, most of the studies are focused on changed anti-oxidation of flavonoids (Yang et al., 2001; Brusselmans et al., 2005). Anti-cancer activities of the flavonoids after heating or oxidative treatments, however, are less assessed so far, and should be paid for special attention.

Heat treatment is a common or necessary step during food cooking or processing, whilst air-oxidation of food components often occurs during food storage. Flavonoid compounds in these processed foods might undergo some chemical changes and therefore have altered anti-cancer activities. In this study, a flavonoid compound apigenin before and after air-oxidative and heating treatments was assessed and compared for its anti-cancer activities to a human colon carcinoma cell line (HCT-116 cells), in terms of anti-proliferation, mitochondrial membrane potential (MMP) loss, death or apoptosis induction, and pro-oxidation. The aim of this study was to reveal possible impacts of the two treatments on anti-cancer activities of apigenin or those apigenin-containing plant foods.

\section{MATERIALS AND METHODS}

\section{Materials and chemicals}

Apigenin (>99\% of purity) was purchased from Shanghai Yousi Biotechnology Co. Ltd. (Shanghai, China). McCoy's
5A medium and trypsin-EDTA solution (containing $2.5 \mathrm{~g} / \mathrm{L}$ trypsin and $0.2 \mathrm{~g} / \mathrm{L}$ EDTA) both were bought from Sigma-Aldrich, Co. (St. Louis, MO, USA). Fetal bovine serum (FBS) was obtained from Hyclone (Logan, UT, USA). Penicillin, streptomycin, Cell Counting Kit8, Cell Cycle and Apoptosis Analysis Kit, Annexin V-FITC Apoptosis Detection Kit, Hoechst 33258 and Mitochondrial Membrane Potential Assay kit with JC-1 were obtained from Beyotime Institute of Biotechnology (Shanghai, China). Dimethyl sulfoxide (DMSO) was purchased from Solarbio Science and Technology Co. Ltd. (Beijing, China). Other chemicals used were of analytical grade. The water used was prepared from Milli-Q Plus system (Millipore, New York, NY, USA).

\section{Apigenin treatments}

Two apigenin solutions (30 and $160 \mathrm{mmol} / \mathrm{L}$ ) were prepared, heated in glass tubes in a thermostatic water bath operated at a normal temperature of food cooking $\left(100^{\circ} \mathrm{C}\right)$ for $30 \mathrm{~min}$ in the dark, and then immediately cooled in ice-water till the solutions reached a temperature of $4^{\circ} \mathrm{C}$. This treatment generated the heated apigenin (i.e. $\mathrm{H}$-apigenin). At the same time, air at $0.2 \mathrm{MPa}$ was introduced continuously from a compressed gas cylinder into the two apigenin solutions via a stainless steel pipe, to conduct air-oxidation of apigenin at room temperature in the dark for $6 \mathrm{~h}$. This treatment obtained the air-oxidized apigenin (i.e. O-apigenin).

The heated and air-oxidized apigenin solutions of $160 \mathrm{mmol} / \mathrm{L}$ were filtrated with $0.22 \mathrm{~mm}$ micro-pore membranes, and then stored at $4^{\circ} \mathrm{C}$ before being used in cell experiments. The treated apigenin solutions of $30 \mathrm{mmol} / \mathrm{L}$ were detected immediately for their absorbencies to generate absorption spectra (wavelength range of 340-400 nm), using an UV-visible spectrophotometer (UV2401 PC, Shimadzu Co., Kyoto, Japan).

\section{Cell line and culture conditions}

A human colorectal cancer cell line (HCT-116 cells) was obtained from the Cell Bank of Shanghai Institute of Biochemistry and Cell Biology (Shanghai, China). The cells were recommended to be cultured in the McCoy's $5 \mathrm{~A}$ medium, supplemented with $10 \% \mathrm{FBS}$ and maintained at $37^{\circ} \mathrm{C}$ in a humidified incubator with $5 \% \mathrm{CO}_{2}$. The cells were sub-cultured every $2 \mathrm{~d}$, and used for the experiments after reaching the exponential growth phase.

\section{Hoechst 33258 staining}

Hoechst 33258, a bis-benzimidazole derivative compound capable of binding the minor groove of DNA, was used for DNA staining to show cell death. Hoechst stains completely dissolve in aqueous solutions and emit blue light under UV excitation. The cells $\left(1 \times 10^{4}\right.$ per chamber) were seeded into 
6-well plates, and treated with apigenin, $\mathrm{O}$-apigenin, and $\mathrm{H}$-apigenin at $160 \mathrm{mmol} / \mathrm{L}$ for $24 \mathrm{~h}$, respectively. After this incubation, the cells were fixed with $4 \%$ methanol at $4{ }^{\circ} \mathrm{C}$ for $10 \mathrm{~min}$. A phosphate buffered solution (PBS, $0.01 / \mathrm{mol} / \mathrm{L}$, $\mathrm{pH}$ 7.0) was used to wash the cells twice. After then, the cells were stained with $200 \mathrm{ng} / \mathrm{mL}$ Hoechst 33258 for $10 \mathrm{~min}$. Representative images were taken by a fluorescence microscope (Zeiss Axio Observer A1, Germany) at $350 \mathrm{~nm}$ with an objective of 40 -fold.

\section{CCK-8 assay of growth inhibition}

Dehydrogenases from living cells can reduce the WST8 [2-(2-methoxy-4-nitrophenyl)-3- (4-nitrophenyl)-5(2,4-disulfophenyl)-2H-tetrazolium, monosodium salt] into a water-soluble orange-color radioactive formazan. The number of living cells is thus in proportion to the generated formazan amount (Tsantili et al., 2011).

The cells $\left(1 \times 10^{5}\right.$ per chamber $)$ were seeded in 96-well plates and incubated for $24 \mathrm{~h}$ to ensure cell attachment. Apigenin (20, 40, 80, 120, and $160 \mathrm{mmol} / \mathrm{L})$ was added, and the cells were re-incubated at $37^{\circ} \mathrm{C}$ for 24,48 , and $72 \mathrm{~h}$, respectively. At the same time, $\mathrm{O}$-apigenin and $\mathrm{H}$-apigenin $(160 \mathrm{mmol} / \mathrm{L})$ was used to treat the cells at $37^{\circ} \mathrm{C}$ for $24 \mathrm{~h}$. Negative and positive control cells were treated with DMSO (0.1\%) and 5-fluorouracil (5-Fu, $100 \mathrm{mmol} / \mathrm{L})$, respectively. The medium was discarded, and $10 \mathrm{~mL} \mathrm{CCK-8}$ solution $(10 \mathrm{~mL} / 100 \mathrm{~mL}$ in the PBS) was added into each well. After $4 \mathrm{~h}$ incubation, optical density (OD) of each well was detected at $450 \mathrm{~nm}$ using a microplate reader (Bio Rad Laboratories, Hercules, CA, USA). The vehicle-treated cells were taken as $100 \%$ viable. Growth inhibition of each sample was calculated with the following equation.

Growth inhibition ( $\%$ of control $)=$

$$
\frac{O D_{\text {Control }}-O D_{\text {Sample }}}{O D_{\text {Control }}-O D_{\text {Blank }}} \times 100
$$

\section{Detection of MMP loss using JC-1}

The cells $\left(1 \times 10^{6}\right.$ per chamber) were seeded into 6 -well plates overnight, and then treated with apigenin, $\mathrm{O}$-apigenin, and $\mathrm{H}$-apigenin at $160 \mathrm{mmol} / \mathrm{L}$, respectively. DMSO of $0.1 \%$ was also used to treat cells as a negative control. After $24 \mathrm{~h}$ incubation, the cells were re-suspended in fresh medium of $1 \mathrm{~mL}$, and incubated with JC-1 (5,5'6,6'-tetrachloro1,1'3,3'-tetraethyl benzimidazolocarbocyanine iodide) of $1 \mathrm{~mL}$ at $37^{\circ} \mathrm{C}$ for $20 \mathrm{~min}$. Following two washes with the Dulbecco phosphate-buffered saline (DPBS, $0.01 \mathrm{~mol} / \mathrm{L}$, $\mathrm{pH}$ 7.0), the cells were re-suspended in fresh medium of $2 \mathrm{~mL}$, and analyzed by a BD FACSort flow cytometry (BD Immunocytometry-Systems, San Jose, CA, USA) with respective excitation and emission wavelengths of 485 and $590 \mathrm{~nm}$. The obtained data were analyzed using the ModFit LT software (Verity Software House, Inc., Topsham, ME,
USA). The detected MMP loss was reported as green/red ratio as previously described (Pernelle et al., 2011).

\section{Assay of apoptosis induction}

The cells $\left(1 \times 10^{5}\right.$ per chamber) were grown in 6-well plates, and allowed to attachment. DMSO $(0.1 \%$, negative control), apigenin, $\mathrm{O}$-apigenin, and $\mathrm{H}$-apigenin $(160 \mathrm{mmol} / \mathrm{L})$ were applied to treat the cells at $37^{\circ} \mathrm{C}$ for $24 \mathrm{~h}$, respectively. Subsequently, the cells were washed and re-suspended with the ice-cold PBS of $1 \mathrm{~mL}$. The FITC Annexin V Apoptosis Detection Kit was used to evaluate the proportion of apoptotic cells according to the manufacturer's protocol. Briefly, the cells were stained with $10 \mathrm{~mL}$ of PI $(20 \mathrm{mg} / \mathrm{mL})$ and $5 \mathrm{~mL}$ of Annexin V-FITC at room temperature for $15 \mathrm{~min}$ in the dark; afterward, the cells were subjected to FACS analysis by a two-dimensional gating method, using the same flow cytometry (BD Immunocytometry-Systems).

\section{Measurement of intracellular ROS}

Apigenin, O-apigenin, and $\mathrm{H}$-apigenin at $160 \mathrm{mmol} / \mathrm{L}$ were applied to treat the cells at $37^{\circ} \mathrm{C}$ for $24 \mathrm{~h}$. After two washes with the PBS, the cells were re-incubated with $10 \mathrm{mmol} / \mathrm{L}$ DCF-DA (2',7'-dichlorofluorescein) at $37^{\circ} \mathrm{C}$ for $30 \mathrm{~min}$. The cells were washed with fresh McCoy's $5 \mathrm{~A}$ medium, and re-suspended in the medium of $1 \mathrm{~mL}$. The fluorescence intensity was detected using a fluorescence spectrophotometer (F-4500, Hitachi, Tokyo, Japan). The relative ROS levels were then expressed as the percentages of the control as previously described (Zhang et al., 2015).

\section{Statistical analysis}

All reported data were obtained from three independent experiments and analyses, and are expressed as means or means \pm standard derivations. Statistical significance between different groups was analyzed by one-way analysis of variance (ANOVA) with Duncan's multiple range tests, using the SPSS version 13.0 program (SPSS Inc., Chicago, IL, USA). Statistical significance was set at $p<0.05$.

\section{RESULTS AND DISCUSSION}

\section{The effects of two treatments on degradation and anti-proliferation of apigenin}

The untreated apigenin solution and the two treated apigenin solutions were all scanned at the same concentration (30 mmol/L) to obtain their UV spectra. The spectra were recorded and compared to reflect possible apigenin degradation upon the heating and air-oxidative treatments. The obtained results (Fig. 1) demonstrated that the conducted heating and air-oxidative treatments both resulted in partial apigenin degradation, as the heated and air-oxidized apigenin solutions both had lower absorbencies than the untreated apigenin solution. This fact implied that 
chemical structure of apigenin during the two treatments was damaged (e.g. ring-cleavage), which led to decreased absorbency. The applied heating treatment was observed to degrade apigenin severely than the air-oxidative treatment, because the heated apigenin solution showed much lower absorbencies at 340-400 $\mathrm{nm}$ than the air-oxidized solution.

Apigenin, $\mathrm{O}$-apigenin, and $\mathrm{H}$-apigenin were then used in cell culture to assess their anti-proliferation on the HCT116 cells. The results (Fig. 2) showed that apigenin at five dose levels of $20-160 \mathrm{mmol} / \mathrm{L}$ inhibited the growth of the cells in a dose-time-dependent manner, verifying apigenin's anti-cancer activities to the cells. The maximum growth inhibition of apigenin was detected to be $78.5 \%$ if treatment time of the cells was $72 \mathrm{~h}$. When the cells were treated by apigenin for 24,48 , and $72 \mathrm{~h}$, the respective half maximal inhibitory concentration $\left(\mathrm{IC}_{50}\right)$ values of apigenin were calculated to be $91.9,88.4$, and $77.1 \mathrm{mmol} / \mathrm{L}$. Based on these results, apigenin of $160 \mathrm{mmol} / \mathrm{L}$ and a treatment time of $24 \mathrm{~h}$ were applied on the cells in the future evaluation. With these two selections, O-apigenin and $\mathrm{H}$-apigenin were detected to have respective growth inhibition of $65.1 \%$ and $50.1 \%$ on the cells. The two values were lower than that of apigenin (67.4\%), indicating that the two treatments (especially heating treatment) resulted in apigenin decreased growth inhibition.

Flavonoids as natural anti-oxidants are well-known to have instability in aqueous solutions, which depends on chemical structures of flavonoids and medium conditions. Chemical instability of flavonoids therefore brings about concentration loss (i.e. degradation), and has been observed in several researches. Heating of fisetin and quercetin solutions leads to continuously decreased absorption intensities as heating time progresses, as the results of fisetin and quercetin degradation (Wang et al., 2016). During storage, ripe pistachios show decreased total phenolics and flavonoids contents (Tsantili et al., 2011). When apple juice is heated at several temperatures, 39 phenolic compounds show degradation especially at higher temperature (De Paepe et al., 2014). In consistent with these reported results, the heated and air-oxidized apigenin solutions both were observed in this study to have decreased absorbencies at $340-400 \mathrm{~nm}$, which also was the result of apigenin degradation. Flavonoid degradation contains a serial reaction such as oxidation, hydroxylation, and especially ring-cleavage. For example, the chalcan-trione structure of quercetin can be opened by a nucleophilic attack at $\mathrm{C}_{3}$ (Barnes et al. 2013). Surely, degraded products of apigenin had chemical structure different from apigenin. However, the treated apigenin had impaired growth inhibition on the cells than the untreated apigenin. It is thus suggested that intact chemical structure of apigenin is very important to apigenin's anti-proliferative activity.

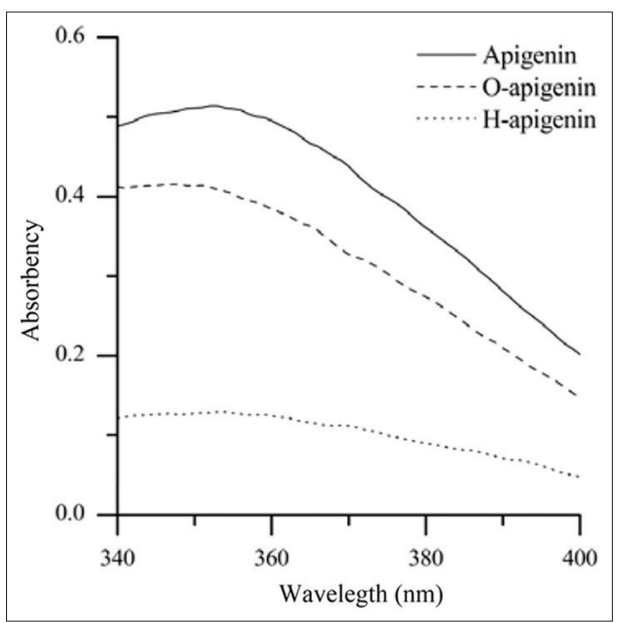

Fig 1. UV spectra of apigenin and the two treated apigenin solutions of $30 \mathrm{mmol} / \mathrm{L}$ scanned at $340-400 \mathrm{~nm}$.

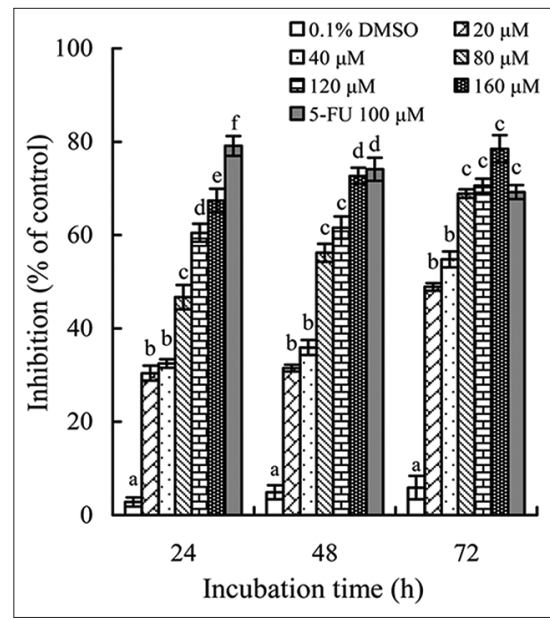

Fig 2. Growth inhibition of apigenin at different dose levels on the HCT-116 cells. All the measurements were conducted three times $(n=3)$, while 5 -fluoruracil (5-F5) was used as positive control. Different lowercase letters above the columns indicate that one-way ANOVA of the mean values at the same incubation time was significantly different $(p<0.05)$.

Anti-oxidant and anti-inflammatory properties of apigenin have been well-studied (Nielse et al., 1999). Anti-cancer, anti-mutagenic, anti-viral, and purgative potentials of apigenin are also studied in the recent years (Nichenametla et al., 2006). The effects of food processing and storage on healthcare functions of apigenin (and more important flavonoids) are thus needed detailed investigation. Flavonoids are sensitive to both heating and oxidative treatments. Heating treatment can cause flavonoid loss in plants and fruits (Ranilla et al., 2009; Zielinski et al., 2009; Igual et al., 2011). However, flavonoids after heating treatment show decreased but relatively high antioxidation, as their degraded products also possess antioxidant activities (Buchner et al., 2006). Oxygen has been found to promote flavonoids' degradation. Higher $\mathrm{CO}_{2}$ (i.e. lower $\mathrm{O}_{2}$ ) level applied in the storage of pomegranate 
fruit results in high maintenance of physiological and biochemical properties (Selcuk et al., 2015). This result indicates an adverse effect of $\mathrm{O}_{2}$ on the bio-activities of flavonoids. In this study, as the result of apigenin degradation, both heating and air-oxidative treatments were proved to have adverse impacts on anti-cancer activities (i.e. anti-proliferation) of apigenin to the cells.

\section{Effects of the two treatments on apigenin's ability to cause MMP loss}

If apigenin, $\mathrm{O}$-apigenin, and $\mathrm{H}$-apigenin were used to treat the cells, the treated cells were detected to have integrity loss of mitochondrial transmembrane depolarization potential (Fig. 3). The results indicated that the cells treated with apigenin severely lost their MMP (shown as much enhanced green/red ratio). However, O-apigenin and especially $\mathrm{H}$-apigenin were detected less powerful than the untreated apigenin to cause MMP loss, as the measured green/red ratios were decreased significantly $(p<0.05)$ in the two cases (especially using $\mathrm{H}$-apigenin). These results indicated that the air-oxidative and especially heating treatments decreased apigenin's ability to cause MMP loss of the cells.

Depolarization of MMP causes the releases of cytochrome c and other apoptosis-inducing factors from the mitochondria into the cytoplasm. Thus, the initiator (i.e. caspase-9) and executioner (i.e. caspase-3) are activated, which afterward leads to the so-called apoptosis. Many natural compounds have been evidenced able to cause MMP loss. Cinnamon can inhibit the growth and break down MMP of the SiHa cells (Koppikar et al., 2010). Physcion can induce mitochondrial apoptosis in the human gastric cancer SGC-7901 cells by reducing MMP and releasing cytochrome c (Xiong et al., 2015). In the human gastric cancer AGS cells, tangeretin induces mitochondrial/caspase-dependent apoptosis by causing MMP loss and up-regulating pro-apoptotic proteins (Dong et al., 2014). This study also proved that apigenin or the treated apigenin could cause MMP loss in the HCT-116 cells. Unfortunately, air-oxidative and especially heating treatments of apigenin led to structure changes and consequentially resulted in weaker ability to cause MMP loss.

\section{Effects of the two treatments on cell death induction of apigenin}

Potential cell death induction of apigenin and the treated apigenin to the HCT-116 cells was firstly reflected by the Hoechst 33258 staining. Compared with the control cells treated by DMSO (Fig. 4a), the cells treated with apigenin showed typical morphology in terms of condensation and fragmentation of nuclei shrinkage, and formation of apoptotic bodies (Fig. 4b). It is thus briefly proved that apigenin could induce cell death in the cells. O-apigenin and $\mathrm{H}$-apigenin both were also able to induce cell death;

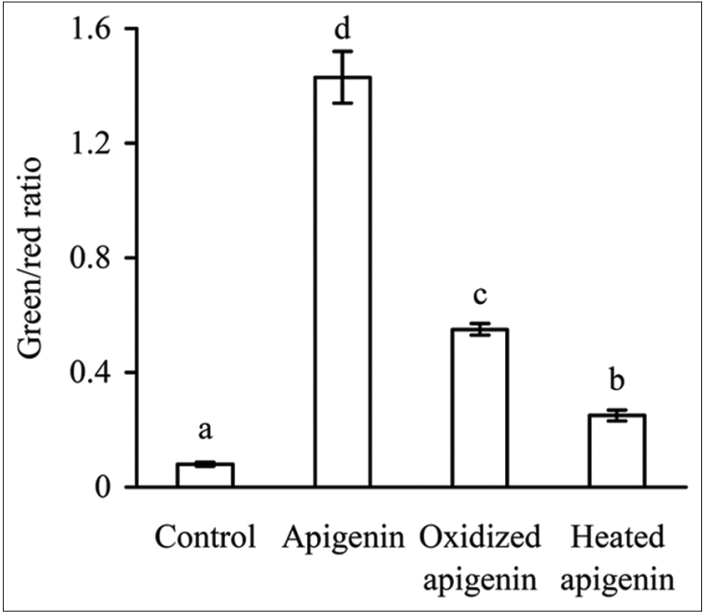

Fig 3. Detected MMP loss of the HCT-116 cells induced by apigenin, $\mathrm{O}$-apigenin, and $\mathrm{H}$-apigenin at $160 \mathrm{mmol} / \mathrm{L}$. JC-1 was excited with the $490 \mathrm{~nm}$ argon laser. JC-1 green was recorded with $(530 \pm 15) \mathrm{nm}$ band pass filter channel, while JC-1 red was recorded with $(590 \pm 13) \mathrm{nm}$ band pass filter channel.
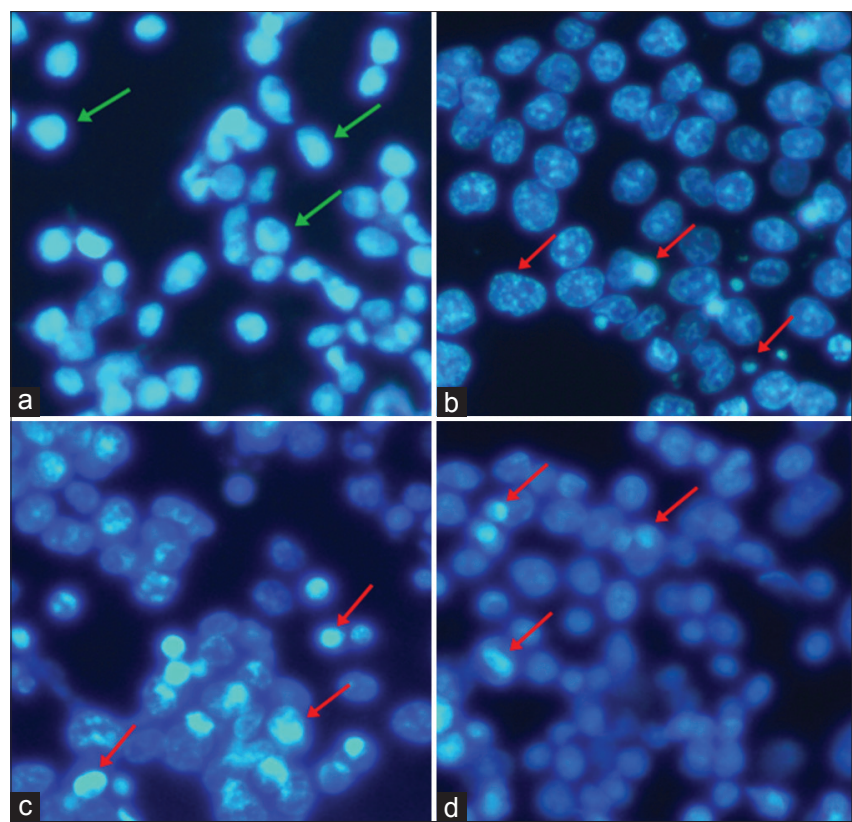

Fig 4. Typical morphology of the control HCT-116 cells (a) and these cells treated by apigenin (b), O-apigenin (c), and $\mathrm{H}$-apigenin (d). Apigenin, O-apigenin, and $\mathrm{H}$-apigenin were all used at $160 \mathrm{mmol} / \mathrm{L}$. A fluorescence microscope was used to photographed images (40X). The control cells had normal nuclei whereas the apoptotic cells showed nuclei shrinkage, condensed chromatin, and apoptotic bodies. Green arrows indicate non-apoptotic cells whereas red arrows indicate condensed chromatin and apoptotic bodies.

however, they were observed with weaker induction than the untreated apigenin, as fewer cells were observed with typical death morphology in the two cases (Fig. 4b versus Fig. $4 \mathrm{c}$ and $\mathrm{d})$.

Apoptosis induction of apigenin or the treated apigenin to the cells was then assessed by flow cytometry using 
the Annexin V-FITC/PI double staining. As seen from these obtained results (Fig. 5), the cells treated with apigenin had total apoptotic cells (Q2 + Q4) about 29.3\% (Fig. 5b). However, the control cells only contained total apoptotic cells about 7.4\% (Fig. 5a). Apigenin treatment of the cells led to an increase in the numbers of apoptotic cells, demonstrating apoptosis induction of apigenin. If $\mathrm{O}$-apigenin and $\mathrm{H}$-apigenin were used to treat the cells, respective total apoptotic cells were detected to be $28.3 \%$ and $8.3 \%$ (Fig. $5 \mathrm{c}$ and d). These results verified that the air-oxidative and especially heating treatments of apigenin led to impaired apoptosis induction. Clearly, these results were consistent with these Hoechst 33258 staining results shown in Fig. 4.

Apigenin does not induce apoptosis in normal cells (Way et al., 2004). Several studies have assessed apoptosis induction of apigenin to some mammalian cancer cells. Apigenin induces the androgen-refractory human prostate cancer PC-3 and DU145 cells apoptosis, associated with release of cytochrome C and deregulation of Bax/ Bcl2 pathway (Shukla et al., 2014). Apigenin causes
DNA fragmentation in the human prostate carcinoma LNCaP cells, and induces apoptosis by cleaving PARP, up-regulating $\mathrm{Bax} / \mathrm{Bcl}-2$ ratio and down-regulating NF-kB/p65 expression (Gupta et al., 2002). Apigenin is capable of inducing caspase-dependent apoptosis in the human bladder cancer cell line (T24 cells), via activating caspase-3, cleaving PARP, and down-regulating Bcl-2 (Zhu et al., 2013). The present results were consistent with these mentioned results, proving apigenin and the treated apigenin had apoptosis induction to the HCT116 cells. However, it was interesting to see that the prior air-oxidative and especially heating treatments of apigenin led to structure damage of some apigenin molecules and therefore, resulted in impaired apoptosis induction.

\section{Effects of the two treatments on pro-oxidation of apigenin}

After being treated with apigenin or the treated apigenin, the cells were assessed for their intracellular ROS generation, to reflect the pro-oxidation of apigenin or the treated apigenin. Apigenin and the treated apigenin were able to enhance ROS generation in the cells (Fig. 6).

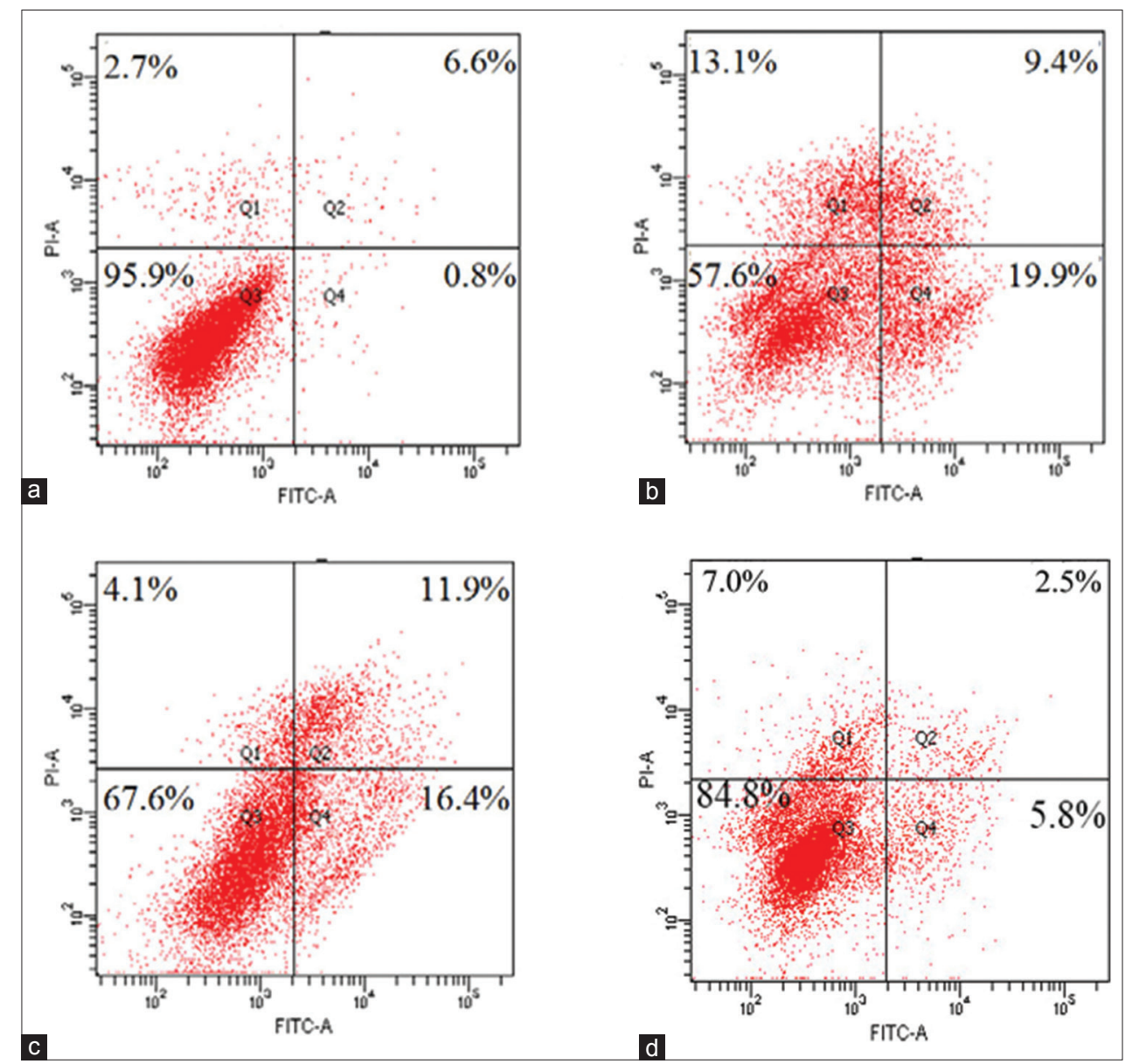

Fig 5. Apoptosis induction of apigenin and the treated apigenin assayed by flow cytometry. The HCT-116 cells were incubated with $0.1 \%$ DMSO (a), 160 mmol/L apigenin (b), O-apigenin (c), and H-apigenin (d). Quadrants 1, 2, 3 and 4 (Q1-4) represent necrosis, late apoptotic, viable, and early apoptotic cells, respectively. All the measurements were conducted three times $(n=3)$, and all data were reported as means. 


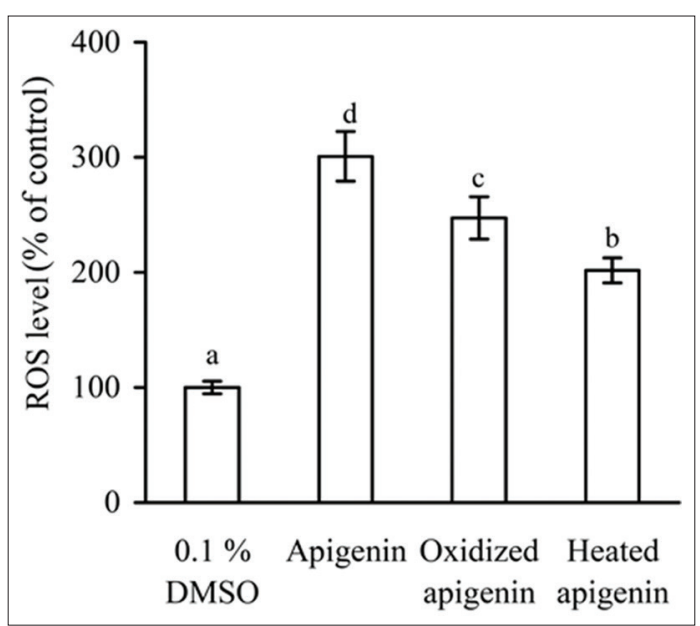

Fig 6. Intracellular ROS levels of the HCT-116 cells treated by DMSO of $0.1 \%$, apigenin O-apigenin, and $\mathrm{H}$-apigenin of $160 \mathrm{mmol} / \mathrm{L}$. Different lowercase letters above the columns indicate that one-way ANOVA of the mean values was significantly different $(p<0.05)$. All the measurements were conducted three times $(n=3)$.

In comparison with the control cells, the cells treated with apigenin had much increase in ROS level (300.7\%), whilst those treated with $\mathrm{O}$-apigenin and $\mathrm{H}$-apigenin had respective $247.3 \%$ and $201.7 \%$ increases in ROS levels. That is, apigenin had stronger pro-oxidation than the treated apigenin $(p<0.05)$. These results indicated that air-oxidative and especially heating treatments were adverse to anti-cancer activities of apigenin in terms of pro-oxidation.

ROS are a group of highly reactive chemicals in the body. In normal conditions, ROS level in the body is controlled by several anti-oxidants. Once the oxidation/anti-oxidation balance in the body is disturbed, the subsequence oxidative stress will occur (Droge, 2002; Sequeda-Castañeda et al., 2016). ROS levels in cancer cells are usually higher than that in normal counterparts. If cancer cells are treated with chemotherapeutic agents and natural anti-cancer compounds, ROS can reach to very high levels, which therefore cause irreversible oxidative damages and induce cell death (Ozben, 2007). Flavonoids can act like prooxidants other than anti-oxidants in cancer cells to increase intracellular ROS levels (Zhang et al., 2015). Apigenin can increase ROS level in the monocytic and HL-60 leukaemic cells (Morrissey et al., 2005). Apigenin, luteolin, kaempferol, and quercetin can induce mitochondrial apoptosis via triggering intracellular ROS production in the human hepatoma HepG2 cells (Vargo et al., 2006). These mentioned studies all agree that apigenin and the treated apigenin could increase ROS generation in the HCT116 cells. However, the prior air-oxidative and especially heating treatments resulted in apigenin degradation, which damaged apigenin's structure and therefore resulted in weaker pro-oxidation.

\section{CONCLUSIONS}

Apigenin had in vitro anti-cancer effects on the human colorectal cancer HCT-116 cells, reflecting by four activities in terms of inhibiting cell growth, inducing death and apoptosis, causing MMP loss, and enhancing intracellular ROS generation. When being heated or air-oxidized, apigenin was partially degraded with changed chemical structure; subsequently, the air-oxidized and especially heated apigenin had weakened anti-cancer activities to the cells than the untreated apigenin. We thus demonstrated for the first time that the four anti-cancer activities of apigenin were susceptible to (and could be weakened by) the air-oxidative and especially heating treatments. Impacts of other food processing on anti-cancer properties of flavonoids or the flavonoid-containing foods are thus suggested for future investigation.

\section{ACKNOWLEDGEMENTS}

This study was supported by the Open Research Fund for Key Laboratory of Dairy Science (Northeast Agricultural University), Ministry of Education of China (Project No. 2015KLDSOF-02), and the Key Research Project in Science \& Technology of The Education Department of Heilongiiang Province (Project No. 11551z018). The authors thank the anonymous reviewers and editors for their valuable advices.

\section{Author contributions}

B. Wang and X. H. Zhao jointly carried out this study, compiled data, conducted the statistical analysis, and wrote the manuscript.

\section{Conflicts of interest}

The authors declare no conflict of interest.

\section{REFERENCES}

Ahmed, D., P. W. Eide, A. Eilertsen, S. A. Danielsen, M. Eknæs, M. Hektoen, G. E. Lind and R. A. Lothe. 2013. Epigenetic and genetic features of 24 colon cancer cell lines. Oncogenesis. 2: 70-71.

Barnes, J. S., F. W. Foss Jr and K. A. Schug. 2013. Thermally accelerated oxidative degradation of quercetin using continuous flow kinetic electrospray-ion trap-time of flight mass spectrometry. J. Am. Soc. Mass Spectrom. 24: 1513-1522.

Brusselmans, K., R. Vrolix, G. Verhoeven and J. V. Swinnen. 2005. Induction of cancer cell apoptosis by flavonoids is associated with their ability to inhibit fatty acid synthase activity. J. Biol. Chem. 280: 5636-5645.

Buchner, N., A. Krumbein, S. Rhon and L. W. Kroh. 2006. Effect of thermal processing on the flavonols rutin and quercetin. Rapid Commun. Mass Spectrom. 20: 3229-3235.

De Paepe, D., D. Valkenborg, K. Coudijzer, B. Noten, K. Servaes, 
M. De Loose, S. Voorspoels, L. Diels and B. Van Droogenbroeck. 2014. Thermal degradation of cloudy apple juice phenolic constituents. Food Chem. 162: 176-185.

Dong, Y., A. L. Cao, J. R. Shi, P. H. Yin, L. Wang, J. Ji, J. Q. Xie and D. Z. Wu. 2014. Tangeretin, a citrus polymethoxy avonoid, induces apoptosis of human gastric cancer AGS cells through extrinsic and intrinsic signaling pathways. Oncol. Rep. 31: 1788-1794.

van Dross, R., Y. Xue, A. Knudson and J. C. Pelling. 2003. The chemopreventive bioflavonoid apigenin modulates signal transduction pathway in keratinocyte and colon carcinoma cell lines. J. Nutr. 133: 3800S-3804S.

Droge, W. 2002. Free radicals in the physiological control of cell function. Physiol. Rev. 82: 47-95.

Escriche, I., M. Kadar, M. Juan-Borras and E. Domenech. 2014. Suitability of antioxidant capacity, flavonoids and phenolic acids for floral authentication of honey. Impact of industrial thermal treatment. Food Chem. 24: 135-143.

Gupta, S., F. Afaq and H. Mukhtar. 2002. Involvement of nuclear factor-kappa B, Bax and $\mathrm{Bcl}-2$ in induction of cell cycle arrest and apoptosis by apigenin in human prostate carcinoma cells. Oncogene. 21: 3727-3738.

Harrison, M. E., M. R. P. Coombs, L. M. Delaney and D. W. Hoskin. 2014. Exposure of breast cancer cells to a subcytotoxic dose of apigenin causes growth inhibition, oxidative stress, and hypophosphorylation of Akt. Exp. Mol. Pathol. 97: 211-217.

Igual, M., E. Garcia-Martinez, M. M. Camacho and N. MartinezNavarrete. 2011. Changes in flavonoid content of grapefruit juice caused by thermal treatment and storage. Innov. Food Sci. Emerg. Technol. 12: 153-162.

Igual, M., E. Garcia-Martinez, M. M. Camacho and N. MartinezNavarrte. 2013. Jam processing and storage effects on $\beta$-carotene and flavonoids content in grapefruit. J. Funct. Foods. 5: 736-744

Jayasooriya, R. G. P., S. H. Kang, C. H. Kang, Y. H. Choi, D. O. Moon, I. W. Hyun, W. Y. Chang and G. Y. Kim. 2012. Apigenin decreases cell viability and telomerase activity in human leukemia cell lines. Food Chem. Toxicol. 50: 2605-2611.

Koppikar, S. J., A. S. Choudhari, S. A. Suryavanshi, S. Kumari, S. Chattopadhyay and R. Kaul-Ghanekar. 2010. Aesqeaurche aortiucles cinnamon extract (ACE-C) from the bark of Cinnamomum cassia causes apoptosis in human cervical cancer cell line $(\mathrm{SiHa})$ through loss of mitochondrial membrane potential. BMC Cancer. 10: 210-214.

Kuete, V., A. T. Mbaveng, M. Zeino, C. D. Fozing, B. Ngameni, G. D. W. Kapche, B. T. Ngadjui and T. Efferth. 2015. Cytotoxicity of three naturally occurring flavonoid derived compounds (artocarpesin, cycloartocarpesin and isobavachalcone) towards multi-factorial drug-resistant cancer cells. Phytomedicine. 11: 83-88.

Marchand, L. L. 2002. Cancer preventive effects of flavonoids-a review. Biomed. Pharmacoth. 56: 296-301.

Marszałek, K., M. Mitek and S. Skąpska. 2015. The effect of thermal pasteurization and high pressure processing at cold and mild temperatures on the chemical composition, microbial and enzyme activity in strawberry purée. Innov. Food Sci. Emerg. Technol. 27: 48-56.

Meyer, H., A. Bolarinwa, G. Wolfram and J. Linseisen. 2006. Bioavailability of apigenin from apiin-rich parsley in humans. Ann. Nutr. Metab. 50: 167-172.

Morrissey, C., A. O’Neill, B. Spengler, V. Christoffel, J. M. Fitzpatrick and R. W. Watson. 2005. Apigenin drives the production of reactive oxygen species and initiates a mitochondrial mediated cell death pathway in prostate epithelial cells. Prostate. 63: 131-142.
Nichenametla, S. N., T. G. Taruscio and D. L. Barney. 2006. A review of the effects and mechanisms of polyphenolics in cancer. Crit. Rev. Food Sci. Nutr. 46: 161-183.

Ozben, T. 2007. Oxidative stress and apoptosis: Impact on cancer therapy. J. Pharm. Sci. 96: 2181-2196.

Park, K., H. S. Park, A. Nagappan, G. E. Hong, D. H. Lee, S. R. Kang, J. A. Kim, J. Zhang, E. H. Kim, W. S. Lee, S. C. Shin, Y. S. Hah and G. S. Kim. 2012. Induction of the cell cycle arrest and apoptosis by flavonoids isolated from Korean Citrus aurantium $L$. in non-small-cell lung cancer cells. Food Chem. 135: 27282735.

Pernelle, K., R. Le Guevel, D. Glaise, C. Gaucher-Di Stasio, T. Le Charpentier, B. Bouaita, A. Corlu and C. Guguen-Guillouzo. 2011. Automated detection of hepatotoxic compounds in human hepatocytes using HepaRG cells and image-based analysis of mitochondrial dysfunction with JC-1 dye. Toxicol. Appl. Pharmacol. 254: 256-266.

Ranilla, L. G., M. I. Genovese and F. M. Lajolo. 2009. Effect of different cooking conditions on phenolic compounds and antioxidant capacity of some selected Brazilian bean (Phaselous vulgaris L.) cultivars. J. Agric. Food Chem. 57: 5734-5742.

Rodríguez-Roque, M. J., B. Ancos, C. Sánchez-Moreno, M. P. Cano, P. Elez-Martínez and O. Martín-Belloso. 2015. Impact of food matrix and processing on the in vitro bioaccessibility of vitamin $\mathrm{C}$, phenolic compounds, and hydrophilic antioxidant activity from fruit juice-based beverages. J. Funct. Foods. 14: 33-43.

Ryan, L. and S. L. Prescott. 2010. Stability of the antioxidant capacity of twenty-five commercially available fruit juices subjected to an in vitro digestion. Int. J. Food Sci. Technol. 45: 1191-1197.

Selcuk, K. and M. M. Erkan. 2015. Changes in phenolic compounds and antioxidant activity of sour-sweet pomegranates cv. 'Hicaznar' during long-term storage under modified atmosphere packaging. Postharvest Biol. Technol. 109: 30-39.

Sequeda-Castañeda, L. G., A. R. Barrera-Bugallo, C. Celis, J. Iglesias, L. Morales. 2016. Evaluation of antioxidant and cytotoxic activity of extracts from fruits in fibroblastoma HT1080 cell lines: Four fruits with commercial potential in Colombia. Emirates J. Food Agric. 28: 143-151.

Shukla, S. and S. Gupta. 2010. Apigenin: A promising molecule for cancer prevention. Pharm. Res. 27: 962-978.

Shukla, S., P. F. Fu and S. Gupt. 2014. Apigenin suppresses inhibitor of apoptosis family protein expression and disrupts Ku70-bax interaction in prostate cancer cells in culture and in vivo. Cancer Res. 4: 5-9.

Siddique, Y. H., T. Beg and M. Afzal. 2008. Antigenotoxic effect of apigenin against anti-cancerous drugs. Toxicol. In Vitro. 22: 625-631.

Trumbo, P. R., A. A. Yates, S. Schlicker-Renfro and C. Suitor. 2003. Dietary reference intakes: Revised nutritional equivalents for folate, vitamin $\mathrm{E}$ and provitamin A carotenoids. J. Food Compos. Anal. 16: 379-382.

Tsantili, E., K. Konstantinidis, M. V. Christopoulos and P. A. Roussos. 2011. Total phenolics and flavonoids and total antioxidant capacity in pistachio (Pistachia vera L.) nuts in relation to cultivars and storage conditions. Sci. Hortic. 129: 694-701.

Vargo, M. A., O. H. Voss, F. Poustk, A. J. Cardounel, E. Grotewold and A. Doseff. 2006. Apigenin-induced-apoptosis is mediated by the activation of PKCठ and caspases in leukemia cells. Biochem. Pharm. 72: 681-692.

Velázquez-Estrada, R. M., M. M. Hernández-Herrero, C. E. Rüfer, B. Guamis-López and A. X. Roig-Sagués. 2013. Influence of ultra high pressure homogenization processing on bioactive compounds and antioxidant activity of orange juice. Innov. Food Sci. Emerg. Technol. 18: 89-94. 
Wang, J. and X. H. Zhao. 2016. Degradation kinetics of fisetin and quercetin in solutions affected by medium $\mathrm{pH}$, temperature and coexisted proteins. J. Serbian Chem. Soc. 81: 243-253.

Wang, W., L. Heideman, C. S. Chung, J. C. Pelling, K. J. Koehler and D. F. Birt. 2000. Cell-cycle arrest at $\mathrm{G}_{2} / \mathrm{M}$ and growth inhibition by apigenin in human colon carcinoma cell lines. Mol. Carcinogen. 28: 102-110.

Way, T., M. Kao and J. Lin. 2004. Apigenin induces apoptosis through proteasomal degradation of HER2/neu in HER2/neu-overexpressing breast cancer cells via the phosphatidylinositol 3-kinase/Akt-dependent pathway. J. Biol. Chem. 279: 4479-4489.

Xiong, Y. X., L. Ren, Z. Q. Wang, Z. C. Hu and Y. J. Zhou. 2015. Anti-proliferative effect of physcion on human gastric cell line via inducing ROS-dependent apoptosis. Cell Biochem. Biophys. 73: 537-543.

Yang, C. S., J. M. Landau, M. T. Huang and H. L. Newmark. 2001. Inhibition of carcinogenesis by dietary polyphenolic compounds. Ann. Rev. Nutr. 21: 381-406.

Yao, Y. and G. X. Ren. 2011. Effect of thermal treatment on phenolic composition and antioxidant activities of two celery cultivars. LWT Food Sci. Technol. 44: 181-185.

Zhang, J., Y. P. Wu, X. Y. Zhao, F. L. Luo, X. Li, H. Zhu, C. Sun and K.
S. Chen. 2014. against cancer cell proliferation and migration. J. Funct. Foods. 9: 511-519.

Zhang, Q., G. D. Cheng, H. B. Qiu, L. L. Zhu, Z. J. Ren, W. Zhao, T. Zhang and L. Liu. 2015. The p53-inducible gene 3 involved in flavonoid induced cytotoxicity through the reactive oxygen species-mediated mitochondrial apoptotic pathway in human hepatoma cells. Food Funct. 6: 1518-1525.

Zhang, Q., X. H. Zhao and Z. J. Wang. 2008. Flavones and flavonols exert cytotoxic effects on a human oesophageal adenocarcinoma cell line (OE33) by causing G2/M arrest and inducing apoptosis. Food Chem. Toxicol. 46: 2042-2053.

Zhang, Q., X. H. Zhao and Z. J. Wang. 2009. Cytotoxicity of flavones and flavonols to a human esophageal squamous cell carcinoma cell line (KYSE-510) by induction of G2/M arrest and apoptosis. Toxicol. In Vitro. 23: 797-807.

Zielinski, H., A. Mishalska, M. Amigo-Benavent, M. D. Del Castillo and M. K. Piskula. 2009. Changes in protein quality and antioxidant properties of buckwheat seeds and groats induced by roasting. J. Agric. Food Chem. 57: 4771-4776.

Zhu, Y., Y. Q. Mao, H. Chen, Y. W. Lin, Z. H. Hu, J. Wu, X. Xu, X. L. Xu, J. Qin and L. P. Xie. 2013. Apigenin promotes apoptosis, inhibits invasion and induces cell cycle arrest of T24 human bladder cancer cells. Cancer Cell Int. 13: 370-373. 